\title{
Albuminuria and hypertension: the chicken or the egg?
}

\author{
Yasuyuki Nagasawa, Yukiko Hasuike, Masayoshi Nanami, Takahiro Kuragano and Takeshi Nakanishi
}

Hypertension Research (2015) 38, 8-10; doi:10.1038/hr.2014.135; published online 4 September 2014

\section{ALBUMINURIA AS THE HATCHED EGG OF HYPERTENSION}

Classically, albuminuria has been attributed to hypertension: in a chicken or egg scenario, albuminuria appears to be the product that 'hatches' from hypertension (Figure 1). Hypertension promotes shearing stress and oxidative stress in endothelial cells. These injured endothelial cells lose the glycocalyx that covers their fenestrae (Figure 2); therefore, they cannot prevent albumin from moving through the basal membrane. ${ }^{1}$ Accordingly, albuminuria is attributed to endothelial cell injury, whereas macroproteinuria is attributed to either injured podocytes or their foot processes. The juxtamedullary nephrons often face conditions characterized by intense hypertension due to vessel strain. Albuminuria has served as an indicator of pressure-associated injury to nephrons. ${ }^{2}$

Several disease conditions, as well as hypertension, also cause proteinuria in a similar manner. ${ }^{3,4}$ Diabetes mellitus is a well-known inducer of albuminuria. ${ }^{5}$ The endothelial surface layer is diminished by the increased expression of heparanase, which is induced by oxidative stress ${ }^{6}$ in the setting of diabetes mellitus; this phenomenon may explain the albuminuria observed in diabetic nephropathy. The negatively charged sugar chains attached to proteoglycans mediate the permselective properties of glomerular endothelial cells. ${ }^{1}$ High concentrations of glucose increase the expression of both dysfunctional endothelial nitric oxide synthase and reactive oxygen species, whereas high doses of free fatty acids do not increase oxidative stress.

Y Nagasawa, Y Hasuike, M Nanami, T Kuragano and T Nakanishi are at Division of Kidney and Dialysis, Department of Internal Medicine, Hyogo College of Medicine, Mukogawa-Cho, Nishinomiya, Japan

E-mail: nagasawa@hyo-med.ac.jp
Dyslipidemia induces albuminuria and proteinuria. The KEEP cohort study reported that dyslipidemia is a predictor of proteinuria and chronic kidney disease, ${ }^{8}$ and the Framingham Offspring cohort also reported that dyslipidemia predicts albuminuria. ${ }^{9}$ Moreover, the treatment of dyslipidemia with statins ameliorates proteinuria in a dose-dependent manner. ${ }^{10-12}$ Smoking is an important factor in endothelial cell damage. Cigarette smoking increases the incidence of end-stage renal disease in IgA nephropathy. ${ }^{13}$ Moreover, the adverse effects of smoking on renal function increase exponentially as the stages of chronic kidney disease increase. ${ }^{14}$ Current smokers have a 1.51-fold higher risk of proteinuria. ${ }^{15}$ These effects are attributed to smokinginduced oxidative stress on endothelial cells. Consequently, albuminuria is a product of hypertension, as well as several other diseases.

\section{ALBUMINURIA AS THE CHICKEN OF HYPERTENSION}

Takahara's cross-sectional study elucidated the relationship between micro-albuminuria and several factors, including hypertension, age, diabetes, metabolic syndrome and diet. ${ }^{16-19}$ Recently, a study by Takahara reported that albuminuria is an independent predictor of cardiovascular mortality on the basis of longitudinal data, ${ }^{20}$ a finding consistent with those of previous studies. ${ }^{21,22}$

In the current issue of Hypertension Research, the Takahata study demonstrates that slight increases in albuminuria may predict incidental hypertension. ${ }^{23}$ During the study's follow-up period (median, 6-7 years), the incidence of hypertension increased compared to baseline urine albumin/creatinine ratio (UACR) values (20.4\% for UACR $<5 \mathrm{mg} \mathrm{g}^{-1}, 34.0 \%$ for $5-9.9 \mathrm{mg} \mathrm{g}^{-1}$ and $40.4 \%$ for $10-29.9 \mathrm{mgg}^{-1}$,
$P$-trend $=0.002)$. The observation period was sufficient to include albuminuria among the causes of hypertension. Moreover, this article reported that subjects with increased UACR values $\left(\geqslant 5 \mathrm{mgg}^{-1}\right)$ had a higher risk of incidental hypertension than those with low UACR values $\left(<5 \mathrm{mgg}^{-1}\right)$, irrespective of their backgrounds (age, sex, smoking, alcohol consumption, obesity and urinary sodium excretion). Aside from pre-hypertension (odds ratio (OR) $3.54 \quad(2.00-6.55)$, $P<0.01)$, the strongest risk factor for hypertension, a UACR of 10.0-29.9 has a higher OR (OR $2.67(1.36-5.38), P<0.01)$ than smoking (OR $1.12(0.61-2.07), P=0.72)$, diabetes (OR $0.62(0.33-1.14), P=0.12$ ) or body mass index (OR 1.08 (0.99-1.18), $P=0.06)$, traditional risk factors for hypertension.

These results indicate that albuminuria acts as a mother figure, or progenitor, for hypertension (Figure 1), in a fashion similar to how smoking, obesity and sodium intake are also considered to be mother figures for hypertension. Hill's criteria are often used to determine causality. ${ }^{24}$ This study has shown that micro-albuminuria appears to cause hypertension in both time-dependent and dose-dependent manners, both of which are important elements of Hill's criteria. The mechanism by which hypertension occurs represents another of Hill's criteria. There are several possible hypotheses that may explain the causality of hypertension as it relates to albuminuria. First, endothelial injury induces albuminuria in the kidneys and hypertension in the entire body (Figure 1). Such endothelial injury may be caused by cigarette smoking, diabetes or dyslipidemia, or by hypertension itself. This theory is similar to the theory depicting albuminuria as the egg to hypertension's chicken. Based on this hypothesis, endothelial injury may be the grandmother of 


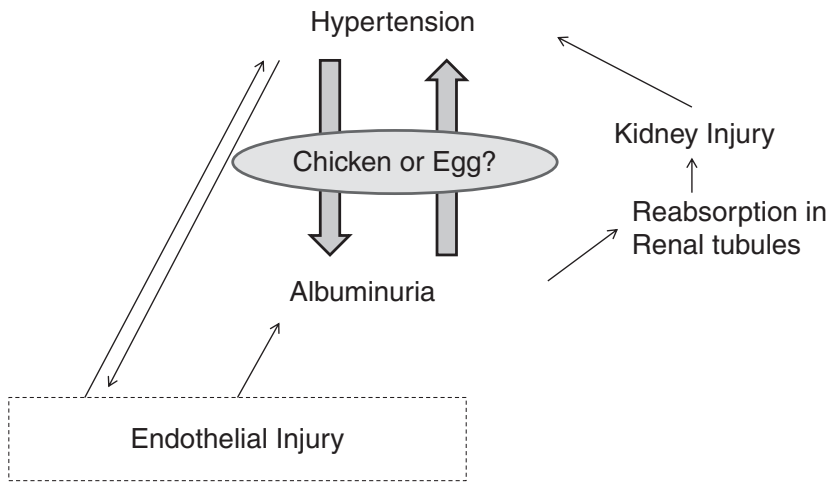

Figure 1 The relationship between hypertension and albuminuria: Chicken or egg. It is difficult to determine whether hypertension causes proteinuria or whether albuminuria causes hypertension based on a single mechanism, as hypertension and albuminuria usually coexist. Hypertension has traditionally been considered an inducer of albuminuria via endothelial injury. Albuminuria, however, may also induce hypertension, as most of the albumin filtered by glomeruli is reabsorbed by the renal tubules, and this albumin may generate oxidative stress, resulting in kidney injury.

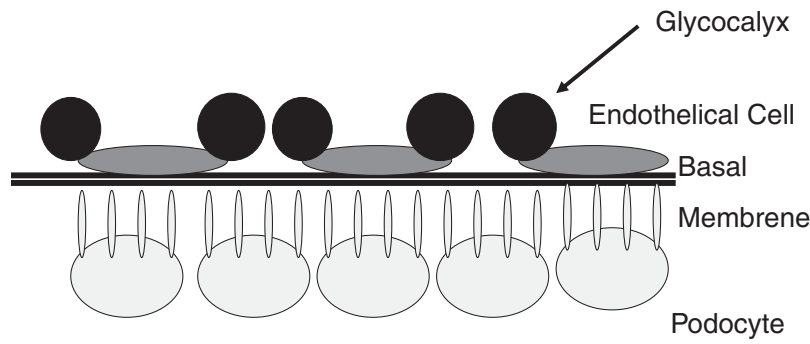

Figure 2 Structure of the filter mechanism in glomeruli. There are two types of cells located in the basal membranes of glomeruli, endothelial cells and podocytes. Podocytes have foot processes that function as filters for albumin. Injury of these foot processes causes nephrotic syndrome. Endothelial cells have fenestrae enough wide for albumin to pass through. The glycocalyx of each endothelial cell covers these fenestrae and has a negative charge; therefore, endothelial cells may also function as filters for albumin. Therefore, albuminuria is basically considered to be caused by injured endothelial cells, whereas macro-proteinuria is considered to be caused by either injured podocytes or their foot processes.

hypertension. Second, albuminuria occurring at the level of the glomeruli is mitigated via the resorption of albumin by the renal tubules. ${ }^{25,26}$ The reabsorbed albumin induces oxidative stress in the renal tubules, resulting in kidney injury, a widely accepted cause of hypertension (Figure 2). If future experimental and clinical reports support this causal link, micro-albuminuria may become more firmly established as the chicken to hypertension's egg.

1 Haraldsson B, Nystrom J, Deen WM. Properties of the glomerular barrier and mechanisms of proteinuria. Physiol Rev 2008; 88: 451-487.

2 Nagasawa T, Mori T, Ohsaki Y, Yoneki Y, Guo Q, Sato E, Oba I, Ito $\mathrm{S}$. Albuminuria indicates the pressureassociated injury of juxtamedullary nephrons and cerebral strain vessels in spontaneously hypertensive stroke-prone rats. Hypertens Res 2012; 35 : 1024-1031.

3 Haraldsson B, Nystrom J. The glomerular endothelium: new insights on function and structure. Curr Opin Nephrol Hypertens 2012; 21: 258-263.

$4 \mathrm{Kim}$ YS, Kim HS, Oh HY, Lee MK, Kim CH, Kim YS, Wu D, Johnson-Levonas $\mathrm{AO}, \mathrm{Oh} \mathrm{BH}$. Prevalence of microalbuminuria and associated risk factors among adult Korean hypertensive patients in a primary care setting. Hypertens Res 2013; 36: 807-823.

5 Nishimura $M$, Kato $Y$, Tanaka T, Todo R, Tone A, Yamada K, Ootani S, Kawabe Y, Yoshizumi H, Hoshiyama Y. Significance of estimating the glomerular filtration rate for the management of hypertension in type 2 diabetes with microalbuminuria. Hypertens Res 2013; 36: 705-710.

6 Kuwabara A, Satoh M, Tomita N, Sasaki T, Kashihara N. Deterioration of glomerular endothelial surface layer induced by oxidative stress is implicated in altered permeability of macromolecules in Zucker fatty rats. Diabetologia 2010; 53 2056-2065

7 Jaimes EA, Hua P, Tian RX, Raij L. Human glomerular endothelium: interplay among glucose, free fatty acids, angiotensin II, and oxidative stress. Am J Physiol Renal Physiol 2010; 298: F125-F132.

8 Whaley-Connell A, Pavey BS, Mccullough PA, Saab G, Li S, Mcfarlane SI, Chen SC, Vassalotti JA, Collins AJ, Bakris G, Sowers JRInvestigators K. Dysglycemia predicts cardiovascular and kidney disease in the Kidney Early Evaluation Program. J Clin Hypertens (Greenwich) 2010; 12: 51-58.

9 O'seaghdha CM, Hwang SJ, Upadhyay A, Meigs JB, Fox CS. Predictors of incident albuminuria in the Framingham Offspring cohort. Am J Kidney Dis 2010; 56: 852-860.

10 Bianchi S, Bigazzi R, Caiazza A, Campese VM. A controlled, prospective study of the effects of atorvastatin on proteinuria and progression of kidney disease. Am J Kidney Dis 2003; 41: 565-570.

11 Bianchi S, Bigazzi R, Campese VM. Intensive versus conventional therapy to slow the progression of idiopathic glomerular diseases. Am J Kidney Dis 2010; 55: 671-681.

12 Toyama T, Shimizu M, Furuichi K, Kaneko S, Wada T. Treatment and impact of dyslipidemia in diabetic nephropathy. Clin Exp Nephrol 2014; 18: 201-205.

13 Yamamoto R, Nagasawa Y, Shoji T, Iwatani H, Hamano T, Kawada N, Inoue K, Uehata T, Kaneko T, Okada N, Moriyama T, Horio M, Yamauchi A, Tsubakihara Y, Imai E, Rakugi H, Isaka Y. Cigarette smoking and progression of IgA nephropathy. $\mathrm{Am} \mathrm{J}$ Kidney Dis 2010; 56: 313-324.

14 Nagasawa Y, Yamamoto R, Rakugi H, Isaka Y. Cigarette smoking and chronic kidney diseases. Hypertens Res 2012; 35: 261-265.

15 Maeda I, Hayashi T, Sato KK, Koh H, Harita N, Nakamura Y, Endo G, Kambe H, Fukuda K. Cigarette smoking and the association with glomerular hyperfiltration and proteinuria in healthy middle-aged men. Clin J Am Soc Nephrol 2011; 6: 2462-2469.

16 Konta T, Hao Z, Abiko H, Ishikawa M, Takahashi T, Ikeda A, Ichikawa K, Takasaki S, Kubota I. Prevalence and risk factor analysis of microalbuminuria in Japanese general population: the Takahata study. Kidney Int 2006; 70: 751-756.

17 Hao Z, Konta T, Takasaki S, Abiko H, Ishikawa M, Takahashi T, Ikeda A, Ichikawa K, Kawata S, Kato T, Kubota I. The association between microalbuminuria and metabolic syndrome in the general population in Japan: the Takahata study. Intern Med 2007; 46: 341-346.

18 Sato M, Hozawa A, Konta T, Shao L, Otani K, Narimatsu H, Sasaki S, Kato T, Kubota I, Yamashita H, Kayama T, Fukao A. Relationship between dietary intake and microalbuminuria: findings from the Takahata study. Clin Exp Nephrol 2012; 16: 147-155.

19 Mashima Y, Konta T, Kudo K, Takasaki S, Ichikawa K, Suzuki K, Shibata Y, Watanabe T, Kato T, Kawata S, Kubota I. Increases in urinary albumin and beta2-microglobulin are independently associated with blood pressure in the Japanese general population: the Takahata Study. Hypertens Res 2011; 34: 831-835.

20 Konta T, Kudo K, Sato H, Ichikawa K, Ikeda A, Suzuki K, Hirayama A, Shibata $Y$, Watanabe $T$, Daimon M, Kato T, Ueno Y, Kayama T, Kubota I. Albuminuria is an independent predictor of all-cause and cardiovascular mortality in the Japanese population: the Takahata study. Clin Exp Nephrol 2013; 17: 805-810.

21 Chronic Kidney Disease Prognosis C, Matsushita K, Van Der Velde M, Astor BC, Woodward M, Levey AS, De Jong PE, Coresh J, Gansevoort RT. Association of estimated glomerular filtration rate and albuminuria with all-cause and cardiovascular mortality in general population cohorts: a collaborative meta-analysis. Lancet 2010; 375: 2073-2081.

22 Wada T, Haneda M, Furuichi K, Babazono T, Yokoyama H, Iseki K, Araki SI, Ninomiya T, Hara S, Suzuki $Y$, Iwano $M$, Kusano $E$, Moriya $T$, Satoh $H$, Nakamura $H$, Shimizu M, Toyama T, Hara A, Makino H, The Research Group of Diabetic Nephropathy $\mathrm{MOHL}$, Welfare Of J. Clinical impact of albuminuria and glomerular filtration rate on renal and 
cardiovascular events, and all-cause mortality in Japanese patients with type 2 diabetes. Clin Exp Nephrol 2014; 18: 613-620.

23 Hirayama A, Konta T, Hozawa A, Kawasaki R, Watanabe T, Shibata Y, Kayama T, Fukao A, Kubota I. Slight increase in urinary albumin excretion within the normal range predicts incident hypertension in a community-based Japanese population: the Takahata study. Hypertens Res 2015; 38 56-60.

24 Hill AB. The environment and disease: association or causation? Proc R Soc Med 1965; 58: 295-300.
25 Dickson LE, Wagner MC, Sandoval RM, Molitoris BA. The proximal tubule and albuminuria: really! J Am Soc Nephrol 2014; 25: 443-453.

26 Birn H, Christensen El. Renal albumin absorption in physiology and pathology. Kidney Int 2006; 69 $440-449$ 